Original Research Paper

\title{
Impact of Micronutrient Soil Deficiency, Crop Residue Usage and Soil Health Assessment on Wheat Crop Productivity: A Study of Indian Punjab
}

\author{
Tanvi Kiran \\ Department of Economics, Panjab University, Chandigarh, India
}

\author{
Article history \\ Received: 31-07-2016 \\ Revised: 21-12-2016 \\ Accepted: 30-03-2017 \\ Email: tanvikiran3@yahoo.com
}

\begin{abstract}
Micronutrient soil deficiency, usage of crop residue and assessment of soil health are the critical factors that have strong bearing on crop productivity. Therefore, in this backdrop, the present study has utilized the econometric tools of ANOVA regression and ordinal logistic regression approach to capture the impact of micronutrient soil deficiency, crop residue usage and soil health assessment on wheat crop productivity across selected wheat growing areas (districts) of Indian Punjab. The empirical analyses pointed out that the farmlands suffering from micronutrient soil deficiency witnessed decreased levels of wheat crop productivity. The results further indicated that farmers are more likely to suffer from low wheat crop productivity and the probability of high wheat yield status of their farmlands is significantly lowered in the absence of crop residue usage and soil health assessment. Thus, from the perspectives of wheat productivity augmentation and provision of higher economic returns, there is a strong need for motivating the farmers to (a) adopt effective soil fertility management practices, (b) utilize crop leftovers to restore the nutrient content of the farming fields and (c) avail soil health assessment facilities and apply fertilizers in amounts recommended by the soil test results.
\end{abstract}

Keywords: Crop Residue Usage, Indian Punjab, Micronutrient Soil Deficiency, Soil Health Assessment, Wheat Crop Productivity

\section{Introduction}

Wheat, an extremely important crop is in much demand over other food crops because of being the staple food crop of India and also due to its abundant nutritional benefits. Punjab, the dominant wheat producing state in India is facing a rather difficult situation, which is evident from the continuous decline in the compound annual growth rate of wheat productivity since $1990 \mathrm{~s}$ (Kumar and Singh, 2012). The decline in wheat productivity and instability in its production as witnessed across different districts of Punjab has been attributed to many factors. One such factor that is assuming critical attention is the deficiency of soil nutrients. The incidence of both macro- and micro-nutrient deficiencies ${ }^{1}$ is fast emerging in the soils of Punjab (Sadana, 2011). A state of the environment report of Punjab by Tiwana et al. (2007) provided a substantial evidence of micronutrient deficiencies which is attributed to exploitive agriculture practices in the
Indian state of Punjab. The report acknowledged that approximately $49 \%$ soils of Punjab were deficient in zinc, $17 \%$ in iron, $3 \%$ in manganese and $2 \%$ soil samples were found to be deficient in copper. Ministry of Agriculture, Government of India (2008) stated that the deficiency of soil micronutrients has emerged as a major constraint to the production and productivity of major food grains such as wheat, rice and pulses in India. The ministry in its document reported widespread micronutrient deficiencies in the National Food Security Mission States (NFSM), particularly in Punjab. While, approximately $48 \%$ and $13 \%$ samples were found to be deficient in zinc and boron, respectively, no deficiency was reported in case of manganese and molybdenum. Singh et al. (2009) analyzed soil samples from several Indian states to study the changes in the percentage of zinc deficiency during the past four decades (1968 to 2008). Using the soil critical limit of $0.6 \mathrm{ppm}$ for zinc, the authors found that the percentage of zinc deficiency in Punjab was $53 \%$ during the period $1968-83$ which 
declined to $37 \%$ during $1983-89$. The practice of micronutrient fertilization decreased the zinc deficiency to $27 \%$ during $1988-97$ which further declined to $22.6 \%$ during the period 1997-2008. Though, the percentage of zinc deficiency has declined in Punjab during the past four decades, but soils of Punjab still suffer from sizeable amount of zinc deficiency $(22.6 \%)$ which is considerable enough to adversely affect the yield of food crops in the state. Dhaliwal et al. (2013) on the basis of the soil sample analyses observed that in the absence of effective nutrient management techniques, micronutrient deficiencies (zinc, manganese, iron and boron) are fast appearing in the rice-wheat growing areas of Punjab and in some areas approximately $50 \%$ soils are reported to be deficient in zinc. Hence, the adoption of effective soil fertility enhancement techniques is highly recommended in order to remove the deficit between demand and supply of nutrients so as to attain high levels of crop productivity. Verbree et al. (2015) in their study brought out an interesting observation about the tree Shea (Vitellaria paradoxa C.F. Gaertn) which enhances the soil fertility and crop growth by improving the availability of Zinc in the soils. In an earlier study, an emphasis has been made by Patra et al. (2015) on the management of soil health for sustainable agriculture across diverse production systems so as to support high crop productivity. The study pointed that soil erosion and imbalance use of nutrients are one of the major causes of decline in soil quality in Asia including India and the gradual decline in soil health due to agriculture intensification, improper nutrient management and soil erosion has led to deficiencies of both primary as well as secondary micronutrients.

Since, most farmers are aware about the key macrosoil nutrients (nitrogen, phosphorus and potassium), hence the incidence of their deficiency is generally reduced by day to day application of the conventional fertilizers, while the issue of micronutrient soil deficiency and its critical role in impacting both quantity and quality of the produce has remained in the backdrop. To detect the presence of soil nutrient deficiencies, the Agriculture Department of Punjab has set up 66 soil laboratories which provide free soil testing facilities to the farmers (Grover and Singh, 2010). The practice of periodical testing of soil brings manifold advantages to the famers; firstly, it serves as a diagnostic tool to assess the soil health status of the farmland and helps in identification of specific soil deficiencies which have a limiting effect on crop yield and production. Secondly, it helps in preparing customized soil fertility management strategies which involve suitable and economically feasible application of fertilizers in amounts recommended by the soil test results. Thus, evaluating soil health status through standardized soil tests not only helps the farmers to identify the existence of nutrient specific soil deficiencies in their farmlands but also by applying fertilizers in amounts recommended by soil testing authorities would bring them the higher crop yields and economic returns. However, 'Compendium on Soil Health' released by the Government of India (2012) revealed that although each district in Punjab has its own soil testing laboratory, but the capacity utilization of these laboratories has remained low to the extent of $45 \%$. Since, assessment of soil health is a crucial factor that has a bearing on crop yield in general, so the farmers should be motivated and made aware of its beneficial effects. Among other factors, retaining adequate quantities of crop residue on soil surface is the key to reverse micro- nutrient soil deficiencies and restoring the fertility of soils (Abrol et al., 2005). However, most farmers either indulge in burning the crop residue or disposing it off without realizing its potential importance (Malik et al., 2005). Effective utilization and management of crop leftovers by the farmers can help overturn the incidence of nutrients depletion, thereby supporting enhanced levels of crop yields. Keeping these factors in mind, the present study anticipates that the presence of micronutrient soil deficiency, absence of crop residue usage and non-assessment of soil health shall have a negative impact on wheat productivity levels and shall lower the chances of resulting in high wheat yield status of the farmlands.

Therefore, in this backdrop, the present study deals with specific issues; firstly, to examine the pattern of micronutrient soil deficiency, crop residue usage and soil health assessment by the farmers across selected wheat growing areas (districts) of Punjab. Secondly, to examine the impact of micronutrient soil deficiency, crop residue usage and soil health assessment on wheat productivity by using alternative econometric modelling approaches. While the ordinal logistic regression approach estimates the probability of micronutrient soil deficiency, absence of crop residue usage and nonassessment of soil health in resulting low or high wheat yield status of the farmlands, the ANOVA regression model estimates the effect size of each of these independent variables on wheat crop productivity levels of the farmers. The knowledge emanating from this research would be of immense help to the farmers to adopt effective soil nutrient restoration practices, to get the soils of their agricultural field tested and to effectively utilize the crop residue as a tool to improve soil health. Further, this study would also help the policy makers, the planners and the state government to align and restructure the soil fertility management policies so as to suit the economic needs of the farmers.

\section{Data and Sample Selection}

The present research is based on cross-sectional primary data collected from six selected districts of Punjab through field survey undertaken between the months of September, 2012 to June, 2013. 
Table 1: Details of the sample selected and analytical models used in the study

\begin{tabular}{|c|c|c|c|}
\hline District type & Sample size & ANOVA model & Ordinal logistic model \\
\hline A. Low Wheat Yield Districts & 40 & & \\
\hline Gurdaspur & 20 & The quantitative & The 40 farmlands from \\
\hline Rupnagar & 20 & $\begin{array}{l}\text { dependent variable, } \\
\text { i.e., wheat productivity } \\
\text { figures reported by }\end{array}$ & $\begin{array}{l}\text { the respective districts are } \\
\text { grouped as farming sites } \\
\text { having low, medium and }\end{array}$ \\
\hline B. Medium Yield Districts & 40 & farmers across 120 & high wheat yield status to \\
\hline Nawanshahr & 20 & farmlands is regressed & study the probability of \\
\hline Jalandhar & 20 & $\begin{array}{l}\text { on qualitative } \\
\text { independent variables, }\end{array}$ & $\begin{array}{l}\text { Micronutrient soil } \\
\text { deficiency, Crop residue }\end{array}$ \\
\hline C. High Yield Districts & 40 & i.e., Micronutrient soil & usage and Soil health \\
\hline Sangrur & 20 & deficiency, Crop & assessment in resulting \\
\hline Moga & 20 & $\begin{array}{l}\text { residue usage and Soil } \\
\text { health assessment }\end{array}$ & $\begin{array}{l}\text { low and high wheat yield } \\
\text { status of the farmlands }\end{array}$ \\
\hline Total & 120 & & \\
\hline
\end{tabular}

Source: Author's Formulation.

On the basis of information obtained from Government of Punjab (Statistical Abstract, 2010-11), two highest wheat yield districts, two medium wheat yield districts (closest to state's average wheat yield value) and two lowest wheat yield districts of Punjab were selected ${ }^{2}$. In order to assess the presence of micronutrient soil deficiency, the soil samples were randomly collected from 120 farmlands located across six selected wheat growing districts of Punjab (20 farmlands from each district) during September, 2012 to November, 2012. The soil samples were analyzed by Panjab University research laboratory for the estimation of available levels ${ }^{3}$ of five micro-soil nutrients (zinc, manganese, copper, iron and boron), which were then compared with their respective critical levels so as to assess the presence of micronutrient soil deficiency across each selected district of Punjab. The farmlands were re-visited during April, 2013 to June, 2013 and wheat yield per hectare as reported by the farmers was noted down. Through personalized interview, the farmers were asked whether they utilize the free soil testing facilities offered by the state to assess the health status of their soils and apply fertilizers based on soil test recommendations or not. They were also inquired that whether they recycled the crop waste by using crop residues as a method of soil nutrient restoration or not.

In the present study, all the independent variables, i.e., micronutrient soil deficiency, crop residue usage and soil health assessment, are qualitative in nature and hence are converted into dummy variables. However, wheat crop productivity is treated both as quantitative and qualitative dependent variable, therefore the econometric tools of ANOVA regression and ordinal logistic regression approaches have been used to capture the impact of micronutrient soil deficiency, crop residue usage and soil health assessment on wheat productivity. The details of the sample selected and the type of the regression model used for the purpose of the study are presented in Table 1. The analytical methods and econometric models used in the present study are discussed in detail in the subsequent section.

\section{Methodology, Regression Diagnostics and Hypotheses}

\section{Use of Soil Critical Levels}

The available levels of soil nutrients as estimated by the standardized soil tests by the Panjab University research laboratory are compared with their respective critical levels so as to assess the presence of deficiency of a soil nutrient. The critical levels of soil nutrients are the threshold levels separating the sufficient from deficient levels of soil nutrients (Silvertooth, 2001). When the available level of an essential soil nutrient is found to be below the critical values as prescribed by Ministry of Agriculture, Government of India (2011), then the soil of a given area is considered to be deficient in that nutrient. The critical levels for micronutrients, recommended by Ministry of Agriculture for the Indian soils as presented in Table 2, have been utilized in the present study to determine the percentage of micronutrient soil deficiency across the selected wheat growing districts of Punjab.

\section{ANOVA Regression Analysis}

When quantitative dependent variable is regressed on independent variables, which are qualitative in nature, then such models are known as ANOVA regression models. Since, each qualitative independent variable in the present study is dichotomous in nature, therefore one dummy variable has been constructed for each of the independent variable as shown in Table 3 . The category for which no dummy variable is assigned is known as the benchmark or the reference category against which all the comparisons are drawn. The 
benchmark category in the present study is represented by the non-deficiency of micro-soil nutrients, usage of crop residue and the soil health assessment (and the subsequent fertilizer application in recommended amounts). Further, the per hectare wheat yield of each of the 120 farmlands located within their respective districts was recorded in order to examine the impact of micronutrient soil deficiency, crop residue usage and soil health assessment on wheat crop productivity levels. Since in this case, wheat yield is treated a quantitative dependent variable, hence for the impact assessment of the chosen independent variables on wheat productivity, the ANOVA regression approach has been used.

Using the ANOVA framework, the functional relation between the dependent variable and the independent variables is expressed as:

$$
\begin{aligned}
& Y_{i}=\beta_{0}+\beta_{1} D_{Z n}+\beta_{2} D_{M n}+\beta_{3} D_{C u} \\
& +\beta_{4} D_{F e}+\beta_{5} D_{B}+\beta_{6} D_{C R D}+\beta_{7} D_{S H A}+U_{i}
\end{aligned}
$$

\section{Where:}

$Y_{i}$

$\beta_{0}$ $\beta_{i}$ $=$ ith differential intercept coefficient, $i$ $=1,2,3,4,5,6,7$

$D_{Z n}, D_{M n}, D_{C u}, D_{F e}$, $D_{B}, D_{C R D}$ and $D_{S H A}$ $U_{i}$

$=$ Stochastic error term

\section{Ordinal Logistic Regression Analysis}

The farmlands from the respective districts of Punjab were grouped and labelled as farming sites having low, medium and high wheat yield status, thereby treating wheat productivity as a qualitative dependent variable having three ordered categories (low, medium and high). To analyse the qualitative dependent variable, the classical linear regression model based on the Ordinary Least Squares (OLS) is inappropriate as it leads to nonnormal residual terms and heteroscedastic variances (Greene, 2012). This problem could be overcome by the application of logistic and probit models based on Maximum Likelihood Estimation (MLE), which provide parameter estimates that are asymptotically consistent and efficient. Since, the medium yield refers to the average or normal yield of the wheat crop, therefore in the present study, our research interest was focused on estimating the probability of micronutrient soil deficiency, absence of crop residue usage and nonassessment of soil health in resulting low and high wheat yield status of the farmlands through ordinal logistic regression analysis.

Table 2: Critical levels of micronutrients advocated for Indian soils

\begin{tabular}{lll}
\hline Name of the micronutrient & Symbol & Critical level in soil \\
\hline Zinc & $\mathrm{Zn}$ & $<0.6 \mathrm{ppm}$ \\
Manganese & $\mathrm{Mn}$ & $<2 \mathrm{ppm}$ \\
Copper & $\mathrm{Cu}$ & $<0.2 \mathrm{ppm}$ \\
Iron & $\mathrm{Fe}$ & $<2.5 \mathrm{ppm}$ \\
Boron & $\mathrm{B}$ & $<0.5 \mathrm{ppm}$ \\
\hline
\end{tabular}

Note: i) 'ppm' refers to parts per million.

ii) The critical levels are generally accepted reference values and are widely followed at the national level for assessing the presence of micronutrient soil deficiencies.

Source: Methods Manual Soil Testing in India, Ministry of Agriculture (2011).

Table 3: Description of the independent variables used in both ANOVA and logistic regression models

\begin{tabular}{lllll}
\hline Symbol & Unit & & Description mean & Standard deviation \\
\hline$D_{\mathrm{Zn}}$ & Binary & Dummy $=1$ for Zinc Deficiency; = 0 for otherwise & 0.25 & 0.434 \\
$D_{\mathrm{Mn}}$ & Binary & Dummy = 1 for Manganese Deficiency; =0 for otherwise & 0.08 & 0.278 \\
$D_{\mathrm{Cu}}$ & Binary & Dummy = 1 for Copper Deficiency; =0 for otherwise & 0.38 & 0.488 \\
$D_{\mathrm{Fe}}$ & Binary & Dummy = 1 for Iron Deficiency; = 0 for otherwise & 0.33 & 0.473 \\
$D_{\mathrm{B}}$ & Binary & Dummy = 1 for Boron Deficiency; =0 for otherwise & 0.58 & 0.496 \\
$D_{\mathrm{CRD}}$ & Binary & Dummy = 1 for No Usage of Crop residue; =0 for otherwise & 0.56 & 0.499 \\
$D_{\mathrm{SHA}}$ & Binary & $\begin{array}{l}\text { Dummy }=1 \text { for No Soil Health Assessment and did not } \\
\text { follow soil test based recommendation; =0 for otherwise }\end{array}$ & 0.75 & 0.435 \\
\hline
\end{tabular}

Source: Author's Formulation/Calculations 
In an ordinal logistic model, where $Y_{i}$ is a qualitative dependent variable and has ' $k$ ' ordered categories, then the cumulative probabilities (Prob.) of being at or below the ith category is given by:

$\operatorname{Prob}\left(Y_{i} \leq i\right)=p_{1}+\ldots+p_{i}$

In general sense, the cumulative logits are the natural $\log$ of odds, which is the probability that a farmland will have a low wheat status versus the probability that it will have a medium or high wheat yield status and are given by:

Cumulative logits $=\operatorname{Logit}\left(Y_{i} \leq i\right)=\log \left(\frac{p(Y \leq i)}{1-p(Y \leq i)}\right)$

In the present study, the natural log of odds can be estimated as a linear function of the following set of explanatory variables:

$$
\begin{aligned}
& \operatorname{Logits}\left(Y_{i} \leq i\right)=\alpha_{i}+\sum \theta_{k} D_{k}+\varepsilon_{i} \\
& \sum \theta_{k} D_{k}+\theta_{1} D_{Z n}+\theta_{2} D_{M n}+\theta_{3} D_{C u} \\
& +\theta_{4} D_{F e}+\theta_{5} D_{B}+\theta_{6} D_{C R D}+\theta_{7} D_{S H A}
\end{aligned}
$$

Where:

$Y_{i}=$ Dependent variable (wheat yield status) with 3 ordered categories

$\alpha_{i}=$ Threshold points $(i=1,2, \ldots m-1)$. The threshold points are intercept terms or cut off points which separate one ordinal response category from the other

$\theta=$ Vector of logistic regression coefficients

$D=$ Vector of independent variables

$k=1,2,3, \ldots \ldots, k$, where $k$ is the total number of independent variables presented in Table 3

$\varepsilon_{i}=$ is the stochastic residual term.

\section{Regression Diagnostics}

The econometric models are based on certain key underlying assumptions, the violation of which may render the inferences to be invalid and dubious. Thus, after specifying the regression models, it is important to run the diagnostic tests to check for the violations of the necessary assumptions on which the models are based. The ANOVA regression model is primarily based on assumption of absence of both multicollinearity and autocorrelation $^{4}$; normality of the error term; presence of homoscedasticity and correct model specification. The ordinal logistic regression model which utilizes Maximum Likelihood method for estimation of the coefficients is based on fewer and less restrictive assumptions of proportional odds ${ }^{5}$; presence of ordinal nature of the dependent variable and absence of multicollinearity. The outcome of the various diagnostic tests for both the econometric models has been presented in Table 4. Variance Inflating Factor (VIF), the widely used collinearity diagnostic measure has been used to detect the presence of multicollinearity in ANOVA regression models. When the VIF of a variable is found to be more than 10 , then the regression model is said to suffer from the problem of high degree of multicollinearity (Field, 2005). Since, the VIF values as shown in Table 4 were found to be less than 10 with respect to each of the variable, so it can be deduced that the ANOVA model does not suffer from the problem of multicollinearity. Further, the standard error of each of the independent variables was observed to be less than 2 (a standard error greater than 2 indicates the presence of multicollinearity in the logistic regression model), therefore multicollinearity problem was not detected in logistic regression model.

The assumption of normality of the error term was tested through the application of Jarque-Bera test, whose $\mathrm{p}$-value was observed to be greater than the chosen alpha level $(0.831>0.05)$, thereby indicating that error term of the model is normally distributed. Likewise, the $\mathrm{p}$ values of Harvey's test $(0.367>0.05)$ and Score test $(0.158>$ 0.05 ) were observed to be statistically insignificant, which implied that the homoscedasticity and proportional odds assumption were also fulfilled by the ANOVA and logistic regression models, respectively. Further, the p-value of the White's test, which was used to test the presence of specification bias in the model, was also observed to be statistically insignificant $(0.173$ $>0.05)$, thereby validating that the ANOVA regression model is correctly specified. Since, all the key assumptions of both the regression models have been met, therefore the regression models are deemed to be valid, thereby indicating that the subsequent inference results can be relied and trusted upon.

\section{Main Hypotheses of the Study}

\section{Micronutrient Soil Deficiency}

On the basis of research evidence, it is expected that deficiency of micro-soil nutrients shall have deterring impact on wheat crop productivity. Further, the deficiency of a micro-soil nutrient is supposed to have a lower probability of resulting in high wheat yield status and is expected to have a higher probability of resulting in low wheat yield status of the farmlands.

\section{Crop Residue Usage}

Usage of crop residue can lead to removal of soil nutrient deficiencies in the soils, however it is expected that the farmers who do not adopt the practice of crop residue usage shall have higher probability that their farmlands will suffer from low wheat status. It is thus, anticipated that the absence of crop residue usage shall have negative effect on wheat productivity levels and would have low chances of resulting in high wheat yield status of the farmlands. 
Table 4: Regression diagnostics

\begin{tabular}{|c|c|c|c|c|c|c|c|}
\hline & $\begin{array}{l}\text { Zinc } \\
\text { Deficiency }\end{array}$ & $\begin{array}{l}\text { Manganese } \\
\text { Deficiency }\end{array}$ & $\begin{array}{l}\text { Copper } \\
\text { Deficiency }\end{array}$ & $\begin{array}{l}\text { Iron } \\
\text { Deficiency }\end{array}$ & $\begin{array}{l}\text { Boron } \\
\text { Deficiency }\end{array}$ & $\begin{array}{l}\text { No Crop } \\
\text { Residue Usage }\end{array}$ & $\begin{array}{l}\text { No Soil Health } \\
\text { Assessment }\end{array}$ \\
\hline $\begin{array}{l}\text { VIF for detecting } \\
\text { Multicollinearity in } \\
\text { ANOVA model }\end{array}$ & 1.152 & 1.051 & 1.118 & 1.164 & 1.195 & 1.119 & 1.109 \\
\hline $\begin{array}{l}\text { Estimation of Standard } \\
\text { Errors for detecting } \\
\text { Multicollinearity in the } \\
\text { logistic model }\end{array}$ & 0.497 & 0.759 & 0.433 & 0.440 & 0.425 & 0.418 & 0.487 \\
\hline $\begin{array}{l}\text { Jarque-Bera test of } \\
\text { normality }\end{array}$ & $0.371(0.831)$ & & & & & & \\
\hline $\begin{array}{l}\text { Harvey's test of } \\
\text { heteroscedasticity }\end{array}$ & $7.615(0.367)$ & & & & & & \\
\hline $\begin{array}{l}\text { Score test of } \\
\text { proportional odds } \\
\text { assumption }\end{array}$ & $10.587(0.158)$ & & & & & & \\
\hline $\begin{array}{l}\text { White's test of model } \\
\text { specification }\end{array}$ & $34.887(0.173)$ & & & & & & \\
\hline
\end{tabular}

\section{Soil Health Assessment and Applying Fertilizers based on Soil Test Recommendations}

Soil testing facilities help in assessing the soil health of the farming fields. It is anticipated that the farmers who do not avail the soil test facilities and also do not follow soil test based fertilizer recommendations, are less likely to have high wheat yield status of their farmlands. Thus, such farmers are expected to register reduced levels of wheat productivity and their farming sites are more likely to suffer from low wheat yield status.

\section{Results and Discussion}

\section{Pattern of Soil Nutrient Deficiency, Crop Residue Usage and Soil Health Assessment across the Selected Districts of Punjab}

Among the micro-soil nutrients, it was observed that overall, the highest deficiency was recorded in the boron content $(58 \%)$ followed by deficiency of copper $(38 \%)$, iron $(33 \%)$, zinc $(25 \%)$ and manganese $(8 \%)$ in approximate terms, respectively as shown in Table 5. Sizable variations in the deficiency status of soil nutrients were observed across the selected districts of Punjab. The deficiencies of zinc and iron were observed to be highest in low wheat yield district of Gurdaspur (50\% and 80\% respectively) and lowest in high wheat yield district of Moga (5\% and 10\% respectively). Following the same pattern, the deficiencies of copper and boron were highest in Rupnagar district and lowest in Moga district. While no deficiency of manganese was found in Gurdaspur and Sangrur districts, but a considerable amount of manganese deficiency was recorded in Rupnagar district. It was observed that a large number of farmers in Gurdaspur district did not adopt the practice of crop residue usage $(75 \%)$ and also did not avail the free soil testing facility to get the soil health checked (90\%). When seen in totality, it was found that about $56 \%$ of the farmers did not make use of crop residue to improve the fertility status of their farmlands and $75 \%$ of the farmers did not get their soil health assessed. Nonetheless, it is to be noted that all the $25 \%$ farmers who got their soil health checked also followed the soil test based recommendations and applied fertilizers in the amount prescribed by the soil testing authorities.

Further, Fig. 1 depicts the administrative boundaries of each district and the level of soil deficiency for each micro-soil nutrient. It was observed that Gurdaspur (low wheat yield district) is highly deficient in zinc $\left(\mathrm{Zn}_{3}\right)$ and copper $\left(\mathrm{Cu}_{3}\right)$; severely deficient in iron $\left(\mathrm{Fe}_{4}\right)$ and very severely deficient in boron $\left(\mathrm{B}_{5}\right)$. Rupnagar, which is another low wheat yield district, recorded moderate levels of deficiency in manganese $\left(\mathrm{Mn}_{2}\right)$ and iron $\left(\mathrm{Fe}_{2}\right)$ content; high, severe and very severe levels of deficiency in zinc $\left(\mathrm{Zn}_{3}\right)$, copper $\left(\mathrm{Cu}_{4}\right)$ and boron $\left(\mathrm{B}_{5}\right)$ content, respectively. Nawanshahr (a medium whet yield district) was observed to be moderately deficient in iron $\left(\mathrm{Fe}_{2}\right)$ and copper $\left(\mathrm{Cu}_{2}\right)$, while it recorded high deficiency in case of boron $\left(\mathrm{B}_{3}\right)$. Jalandhar, another medium yield district witnessed moderate levels of deficiency in zinc $\left(\mathrm{Zn}_{2}\right)$, copper $\left(\mathrm{Cu}_{2}\right)$ and boron content $\left(\mathrm{B}_{2}\right)$. With respect to the high wheat yield districts, Sangrur recorded low deficiency levels of zinc $\left(\mathrm{Zn}_{1}\right)$ and manganese $\left(\mathrm{Mn}_{1}\right)$, while Moga witnessed low deficiency levels of copper $\left(\mathrm{Cu}_{1}\right)$, iron $\left(\mathrm{Fe}_{1}\right)$, zinc $\left(\mathrm{Zn}_{1}\right)$ and manganese $\left(\mathrm{Mn}_{1}\right)$. 


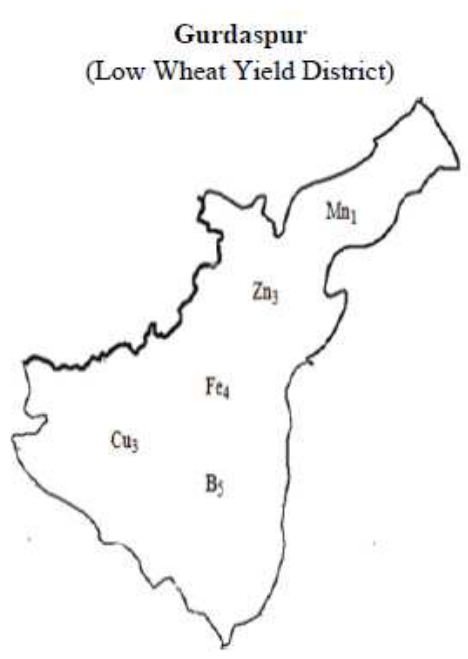

Jalandhar

(Medium Wheat Yield District)

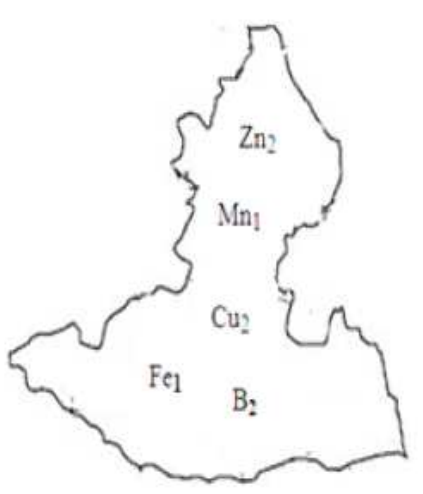

Rupnagar

(Low Wheat Yield District)

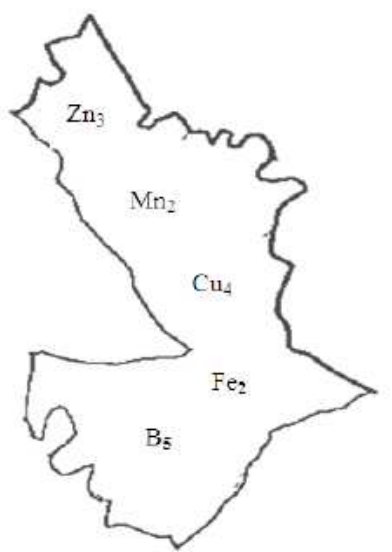

Sangrur

(High Wheat Yield District)

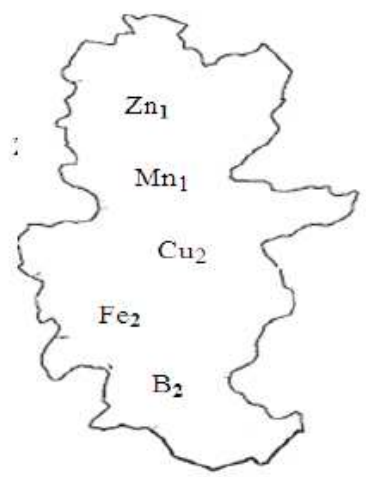

Nawanshahr

(Medium Wheat Yield District)

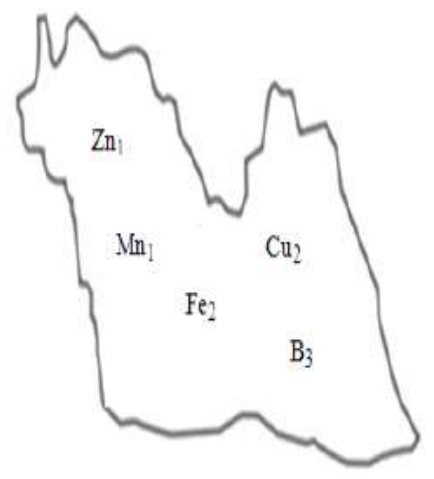

Moga

(High Wheat Yield District)

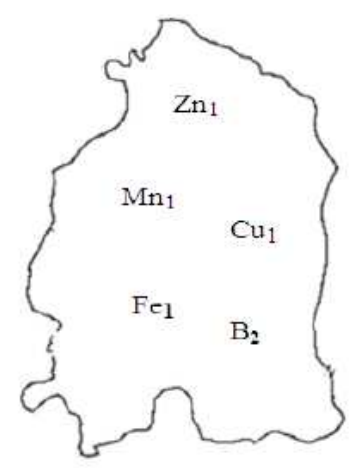

Scale of Micronutrient Soil Nutrient Deficiency

\begin{tabular}{l|c|c}
\hline Percentage of Soil Deficiency & Code & Level of Deficiency \\
Less than $20 \%$ & 1 & Low \\
$20 \%$ to $40 \%$ & 2 & Moderate \\
$41 \%$ to $60 \%$ & 3 & High \\
$61 \%$ to $80 \%$ & 4 & Severe \\
Above $80 \%$ & 5 & Very Severe \\
\hline
\end{tabular}

Fig. 1: Pattern of micronutrient soil deficiency across selected districts of Indian Punjab

Table 5: Pattern of micronutrient soil deficiency, crop residue usage and soil health assessment across the selected districts

\begin{tabular}{llllllll}
\hline Variables & Gurdaspur & Rupnagar & Nawanshahr & Jalandhar & Sangrur & Moga & $\begin{array}{l}\text { Overall } \\
\text { percentage }\end{array}$ \\
\hline Zinc Deficiency $\left(D_{Z n}\right)$ & 50 & 45 & 15 & 25 & 10 & 5 & 25 \\
Manganese Deficiency $\left(D_{M n}\right)$ & 0 & 25 & 15 & 5 & 0 & 5 & 8.33 \\
Copper Deficiency $\left(D_{C u}\right)$ & 55 & 65 & 40 & 20 & 35 & 15 & 38.33 \\
Iron Deficiency $\left(D_{F e}\right)$ & 80 & 35 & 35 & 15 & 25 & 10 & 33.33 \\
Boron Deficiency $\left(D_{B}\right)$ & 90 & 100 & 45 & 40 & 40 & 30 & 57.5 \\
No Crop Residue Usage $\left(D_{C R D}\right)$ & 75 & 70 & 50 & 60 & 35 & 45 & 55.8 \\
No Soil health Assessment $\left(D_{S H A}\right)$ & 90 & 85 & 70 & 85 & 50 & 70 & 75 \\
\hline
\end{tabular}

Source: Author's Calculations. 
Table 6. Estimated coefficients of ANOVA regression model

\begin{tabular}{|c|c|c|c|c|}
\hline Independent variables & Estimated coefficients & Standard errors & t-ratios & p-values \\
\hline Intercept (Constant) & $5627.591\left(\beta_{0}\right)$ & 149.417 & 37.664 & $0.000 * *$ \\
\hline Zinc Deficiency $\left(D_{Z n}\right)$ & $-362.217\left(\beta_{1}\right)$ & 148.603 & -2.437 & $0.008 * *$ \\
\hline Manganese Deficiency $\left(D_{M n}\right)$ & $-307.905\left(\beta_{2}\right)$ & 222.335 & -1.385 & 0.084 \\
\hline Copper Deficiency $\left(D_{C u}\right)$ & $-498.287\left(\beta_{3}\right)$ & 130.364 & -3.822 & $0.000 * *$ \\
\hline Iron Deficiency $\left(D_{F e}\right)$ & $-366.832\left(\beta_{4}\right)$ & 137.234 & -2.673 & $0.004 * *$ \\
\hline Boron Deficiency $\left(D_{B}\right)$ & $-678.813\left(\beta_{5}\right)$ & 132.603 & -5.119 & $0.000 * *$ \\
\hline No Crop Residue Usage $\left(D_{C R D}\right)$ & $-377.94\left(\beta_{6}\right)$ & 127.719 & -2.959 & $0.002 * *$ \\
\hline No Soil Health Assessment $\left(D_{S H A}\right)$ & $-314.564\left(\beta_{7}\right)$ & 145.784 & -2.158 & $0.016^{*}$ \\
\hline \multicolumn{5}{|c|}{ Dependent variable $=$ Wheat productivity $(\mathrm{kg} / \mathrm{ha}) ; \mathrm{n}=120$} \\
\hline \multicolumn{5}{|c|}{ F- statistic $(7,112)=17.38^{* *}$} \\
\hline \multicolumn{5}{|l|}{$\mathrm{R}^{2}=0.5207$, Adjusted $\mathrm{R}^{2}=0.4907$} \\
\hline
\end{tabular}

\section{Decrease in Wheat Crop Productivity: The ANOVA Regression Results}

The reduction in wheat crop productivity due to specific micronutrient soil deficiency, absence of crop residue usage and non-assessment of soil health is indicated by the negative differential intercept coefficient of each of the significant dummy independent variables (Table 6). It can be clearly seen that the negative values of differential intercept coefficients of zinc, copper, iron and boron deficiency were observed to be statistically significant $(\mathrm{p}<0.01)$, thereby indicating that specific micronutrient soil deficiency has a negative bearing on wheat crop productivity. Though, the differential intercept coefficient of manganese, was estimated to be of negative value (-307.905), however it was not found to have a statistically significant negative impact on wheat yield. Amongst the micro- soil nutrients, boron deficiency was observed to have the maximum negative impact on wheat productivity resulting in wheat yield reduction of about $679 \mathrm{~kg} / \mathrm{ha}$ followed by deficiencies of copper, iron and zinc, which resulted in per hectare decrease in wheat crop yield by approximately 498, 367 and $362 \mathrm{~kg}$ respectively.

The coefficients of absence of crop residue usage $\left(D_{C R D}\right)$ and non-assessment of soil health $\left(D_{S H A}\right)$ also have a significant negative impact on wheat productivity levels of the farmers. This observation suggests that the farmers who did not use crop residue as a means to overcome soil nutrient deficiencies had to suffer decreased levels of wheat crop productivity to the tune of $378 \mathrm{~kg} / \mathrm{ha}$. Likewise, farmers who did not get their soil health assessed and did not apply fertilizers based on the soil test recommendations also witnessed reduction in wheat yield by about $315 \mathrm{~kg} / \mathrm{ha}$. The 'goodness of fit' of the model was confirmed by the significant value of the F-test (17.38), which indicated that the observed negative relationship between the dependent variable (wheat yield) and the independent variables (specific micronutrient soil deficiency, absence of crop residue usage and non-assessment of soil health) was statistically reliable. Further, the value of adjusted $R^{2}$ pointed out that together the seven independent variables (deficiencies of zinc, manganese, copper, iron and boron; lack of crop residue usage and non-assessment of soil health) explained approximately $49 \%$ variation in wheat crop productivity levels across the selected districts of Punjab.

Estimation of Wheat Crop Productivity in the Presence and Absence of Micronutrient Soil Deficiency, Crop Residue Usage and Soil Health Assessment

As shown in Table 7, wheat crop productivity in case of non-deficiency of micro- soil nutrients, crop residue usage and soil health assessment (and the subsequent fertilizer application in recommended amounts) was estimated to be $5627.591 \mathrm{~kg} / \mathrm{ha}$ (wheat yield of the benchmark category/the intercept term), which was observed to be considerably more than the average of the wheat productivity figures $\left(\bar{Y}_{i}\right)$ reported by the farmers $(4360.833 \mathrm{~kg} / \mathrm{ha})$. This indicates that the estimated wheat yield in the absence of soil deficiency, usage of crop residue and assessment of soil health was considerably more than the reported average wheat yield of the farmers by about $1267 \mathrm{~kg} / \mathrm{ha}$. In order to estimate wheat crop productivity in the presence of specific micronutrient soil deficiency, absence of crop residue usage and nonassessment of soil health, the differential intercept coefficients of the respective significant independent variables were subtracted from the intercept term. Accordingly, the estimated wheat yield values in the presence of boron, copper, iron and zinc deficiencies (approximately 4949, 5129, 5261 and $5265 \mathrm{~kg} / \mathrm{ha}$, respectively) were observed to be considerably lower than the wheat yield ( $5628 \mathrm{~kg} / \mathrm{ha}$ approximately) of the farmers in the absence of micronutrient soil deficiencies. Likewise, the farmers who did not adopt the practice of crop residue usage and did not avail the soil test facilities (subsequently did not follow soil test based fertilizer 
recommendations) witnessed wheat yield levels (about 5250 and $5313 \mathrm{~kg} / \mathrm{ha}$, respectively) which were significantly lower than the levels witnessed (about 5628 $\mathrm{kg} / \mathrm{ha}$ ) in the event of application of crop residue and assessment of soil health by the farmers. This observation being consistent with the hypotheses of the present study, serves as a substantial piece of evidence on the impeding effect of micronutrient soil deficiency, lack of crop residue usage and non-assessment of soil health on wheat productivity levels of the farmers in the state of Punjab.

\section{Results of the Ordinal Logistic Regression Analysis}

In the present study, ordinal logistic regression has been employed to estimate the probability of each of the independent variable influencing the wheat yield status of the farmlands. The percent distribution of each of the independent variables across the three ordinal categories (low, medium and high wheat yield status) of the dependent variable has been presented in Table 8, which shows that the deficiency of each of the micro-soil nutrient was observed to be highest in farmlands in districts having low wheat yield status than those located in districts with high wheat yield status. A predominant number of farmers whose farming sites were located in districts with low wheat yield status neither got the soil health status assessed and nor did they make use of crop residue to restore the fertility status of their farming fields.

Table 7: Estimated wheat productivity in the presence and absence of micronutrient soil deficiency, crop residue usage and soil health assessment

Estimated wheat yield in the presence of Zinc Deficiency $\left(D_{Z n}\right)$

Estimated wheat yield in the presence of Copper Deficiency $\left(D_{C u}\right)$

Estimated wheat yield in the presence of Iron Deficiency $\left(D_{F e}\right)$

$=5265.374\left(\beta_{0}-\beta_{1}\right)$

$=5129.304\left(\beta_{0}-\beta_{3}\right)$

$=5260.759\left(\beta_{0}-\beta_{4}\right)$

Estimated wheat yield in the presence of Boron Deficiency $\left(D_{B}\right)$

$=4948.778\left(\beta_{0}-\beta_{5}\right)$

Estimated wheat yield in the absence of Crop Residue Usage $\left(D_{C R D}\right)$

Estimated wheat yield in case of Non-Assessment of Soil Health $\left(D_{S H A}\right)$

The estimated wheat productivity in the case of non-deficiency of micro- soil nutrients, usage of crop

$=5249.651\left(\beta_{0}-\beta_{6}\right)$

residue and assessment of soil health is $5627.591 \mathrm{~kg} / \mathrm{ha}$ (the intercept term $\beta_{0} /$ mean value of benchmark category).

$\bar{Y}_{i}=4360.833$ (Mean value of wheat productivity figures reported by the farmers)

Source: Author's Calculations.

Table 8: Distribution of independent variables across the ordinal categories of the dependent variable

\begin{tabular}{llll}
\hline & $\begin{array}{l}\text { Farmlands in } \\
\text { districts having low } \\
\text { wheat yield status }\end{array}$ & $\begin{array}{l}\text { Farmlands in districts } \\
\text { having medium } \\
\text { wheat yield status }\end{array}$ & $\begin{array}{l}\text { Farmlands in } \\
\text { districts having high } \\
\text { wheat yield status }\end{array}$ \\
\hline Zinc Deficiency $\left(D_{Z n}\right)$ & 47.5 & 20 & 7.5 \\
Manganese Deficiency $\left(D_{M n}\right)$ & 12.5 & 10 & 2.5 \\
Copper Deficiency $\left(D_{C u}\right)$ & 60 & 30 & 25 \\
Iron Deficiency $\left(D_{F e}\right)$ & 57.5 & 25 & 17.5 \\
Boron Deficiency $\left(D_{B}\right)$ & 95 & 42.5 & 35 \\
No crop residue usage $\left(D_{C R D}\right)$ & 72.5 & 55 & 40 \\
No soil health Assessment $\left(D_{S H A}\right)$ & 87.5 & 77.5 & 60 \\
\hline
\end{tabular}

Source: Authors' Calculations.

Table 9: Odds ratios and estimated coefficients of ordinal logistic model

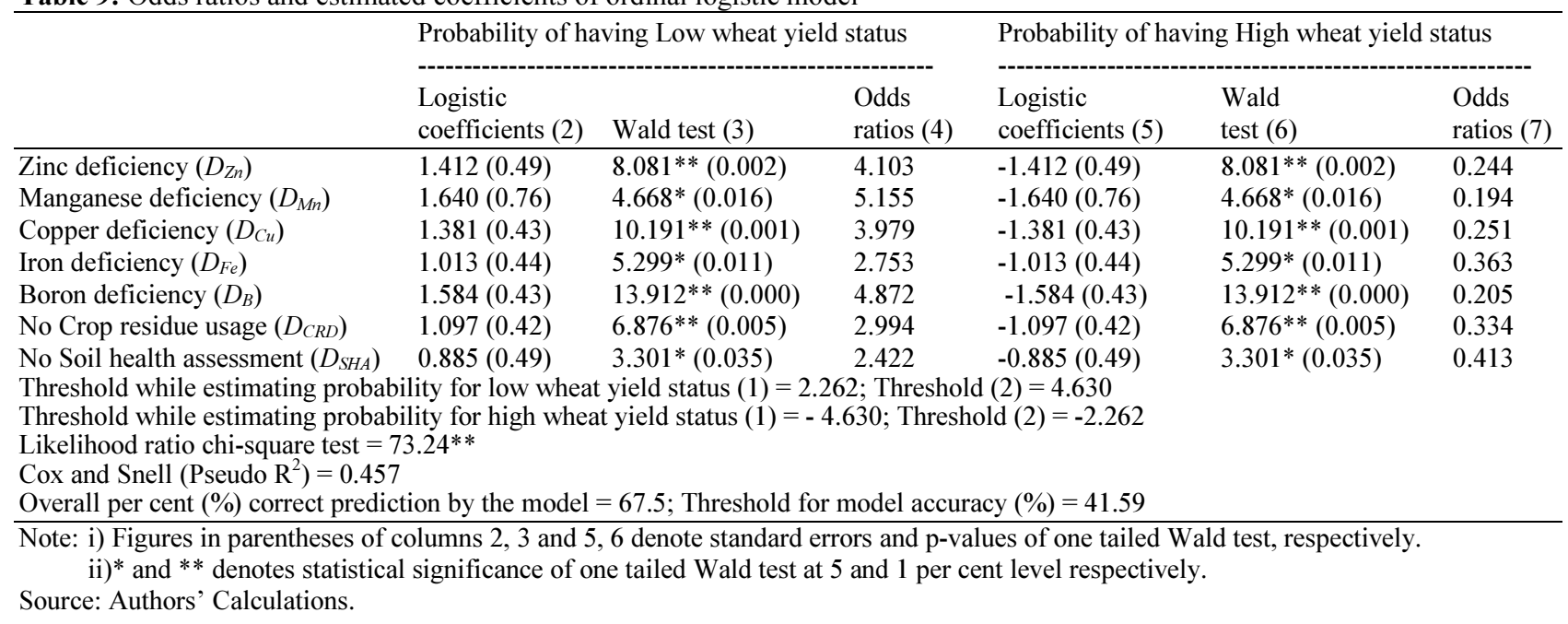


The parameters of the logistic model as presented in Table 9 were estimated through the method of Maximum Likelihood Estimation (MLE). The probability of micronutrient soil deficiency, absence of crop residue usage and non-assessment of soil health in resulting low and high wheat yield status of the farmlands is reflected by the odd ratios. The significance of the individual logistic coefficients for each independent variable was tested through the Wald test, which is analogous to t-test used in regression models based on Ordinary Least Squares (OLS). The estimated logistic regression coefficients for farmlands having low and high wheat yield status had exactly the same values, the only difference being that the coefficients of the high wheat yield status have negative values as compared to the positive values obtained with respect to low wheat yield status. This implies that the odds ratios of each independent variable resulting in high wheat yield status were observed to be less than one, while the odds ratios resulting in low wheat yield status were found to be greater than one. Mathematically speaking, when the odds ratios are estimated to greater than one, it indicates high probability of occurrence of an event, whereas odds ratios of less than one denotes decreased chances of occurrence of an event (Agresti, 2003). Following this criterion, the odds ratios of manganese deficiency and boron deficiency were observed to be 5.155 and 4.872 , which indicate that the probability of resulting in low wheat yield status of the farmlands was estimated to be 5.155 and 4.872 times higher for manganese and boron deficient samples, respectively. Likewise, the farmlands suffering from deficiencies of zinc, copper and iron, respectively had 4.103, 3.979 and 2.753 times greater chances of having low wheat crop productivity status.

Further, the probability that their farmlands will suffer from low wheat yield status was observed to be 2.994 times higher for those farmers who did not adopt the practice of crop residue usage. Similarly, the farmers who did not get the soil health status assessed and also did not follow soil test based fertilizer recommendations had 2.422 times higher chances that their farmlands will suffer from low wheat status. While examining the probability of each of the independent variable resulting in high wheat yield status, it was observed that the odds ratio of manganese deficiency was estimated to be 0.194 , thereby implying that the probability of resulting in high wheat yield status of the farmlands was $80.6 \%$ (1-0.194) lower for manganese deficiency. Going by the same pattern, the deficiencies of boron, zinc, copper and iron were estimated to have respectively 79.5, 75.6, 74.9 and $63.7 \%$ lower probability of resulting in high wheat productivity status of the farmlands. Further, the probability that their farmlands will have high wheat yield status was $66.6 \%$ and $58.7 \%$ lower for those farmers who did not adopt the practice of crop residue usage and did not get the soil health status checked. The Likelihood ratio chi-square test value (73.24) which is a goodness-of-fit test of the overall logistic regression model was observed to be statistically significant at $1 \%$ level, thereby indicating that present model has good estimation fit. The classification accuracy rate as reflected by overall correct prediction of the logistic model was estimated to be $67.5 \%$, which was observed to be much higher than the threshold value of $41.59 \%$. This observation confirms and validates that the ordinal logistic model has a reasonably good level of classification and prediction accuracy. The value of Cox and Snell ${ }^{6}$ Pseudo $\mathrm{R}^{2}$ indicates that the set of seven independent variables (deficiency of five micro-soil nutrients, absence of crop residue usage and nonassessment of soil health) have explained $45.7 \%$ variation in wheat crop productivity status of the farmlands across selected districts of Punjab.

Thus, the results of ANOVA and logistic regression analysis suggest that the farmlands suffering from micronutrient soil deficiency have to bear decreased levels of wheat crop productivity. This observation is supported by Sadana et al. (2010), who on the basis of his research substantiated that micronutrient soil deficiency has a deterring effect on wheat productivity in Punjab. The researchers reported that a significant increase in wheat crop response is possible by reducing the occurrence of soil nutrient deficiencies through application of soil nutrients in recommended amounts. In the absence of crop residue usage and soil health assessment, the farmers are more likely to suffer from low wheat crop productivity and the probability of high wheat yield status of their farmlands is significantly lowered. Thus, there is a vehement need for motivating the farmers to avail the free soil testing facilities offered by the state for soil health assessment and to utilize the crop wastes to restore the nutrient content of the farming fields in the context of achieving enhanced wheat crop productivity levels.

\section{Conclusions and Policy Suggestions}

The study reveals the existence of skewed deficiency pattern of micro-soil nutrients, usage of crop residue and soil testing facility availed by the farmers across the selected districts of Punjab. The low wheat yield district of Gurdaspur was observed highly deficient in zinc and copper; severely deficient in iron and very severely deficient in boron content. Similarly, the other low wheat yield district, Rupnagar recorded high, severe and very severe levels of deficiency in zinc, copper and boron content, respectively. With respect to medium wheat yield districts, Nawanshahr was observed to be highly 
deficient in boron, while Jalandhar recorded moderate levels of deficiency in zinc, copper and boron. In case of the high wheat yield districts, Sangrur witnessed low deficiency levels of zinc and manganese, while Moga registered low deficiency levels of copper, iron, zinc and manganese. Looking at the overall trend, the deficiency of each of the micro-soil nutrient was observed to be relatively greater in low wheat yield districts as compared to the high yield districts. Further, large number of farmers whose farmlands were located in low wheat yield districts neither got the soil health status assessed and nor did they make use of crop leftovers to thwart the emergence of soil nutrient deficiencies. The regression results validated the deterring effect of micronutrient soil deficiency on wheat crop productivity levels of the farmers. In the light of this observation, there is a strong case to innovate and develop smart fertilizers coated with specific micro-soil nutrients so as to overcome and reduce the incidence of their deficiencies that clearly have a negative impact on wheat crop productivity. As anticipated, the farmers who did not avail the soil test facilities and also did not follow soil test based fertilizer recommendations were less likely to enjoy high wheat yield status of their farmlands.

Assessment of the soil health status enables the farmer to make informed decisions regarding the fertility management of their farming fields which can help boost crop response to soil nutrient application. Measures like declaration of state soil testing week, strengthening the soil testing infrastructure and strong campaigning of the beneficial effects of both soil testing and balanced fertilization are warranted to be undertaken by the state government. The empirical results of the study clearly showed that the farmers who did not adopt the practice of crop residue usage had to suffer from decreased levels of wheat yield with lower probability that their farmlands will have high wheat yield status. This observation lends support to the argument that effective management and utilization of the crop leftovers and using it in conjunction with inorganic fertilizers and organic manures through the practice of integrated soil nutrient management can help achieve enhanced levels of wheat crop yield in particular and food crop productivity in general. As a matter of fact, with increased levels of crop productivity, the standard of living and the economic status of the farmers can also be improved. Thus, from both the perspectives of wheat productivity augmentation and provision of higher economic returns to the farmers, there is a fervent need for adopting innovative soil nutrient restoration techniques, promoting effective utilization of the crop leftovers and encouraging the farmers to undertake soil health assessment of their farmlands so as to apply fertilizers in amounts recommended by the soil test results.

\section{Notes}

1. Macronutrients are required in relatively large amounts, whereas micronutrients are the ones that are required in relatively low quantities by the crops for their growth (FAO and IFA, 2000).

2. Since, wheat crop productivity of the entire state of Punjab for the year 2010-11 was $4693 \mathrm{~kg} / \mathrm{ha}$, hence in accordance with the scheme of the sampling design, Sangrur (5128 kg/ha) and Moga (5014 kg/ha) were chosen as the high wheat yield districts; Nawanshahr (4708 kg/ha) and Jalandhar (4690 kg/ha) were selected as the medium wheat yield districts; Gurdaspur (4065 $\mathrm{kg} / \mathrm{ha}$ ) and Rupnagar (3900 kg/ha) were identified as low wheat yield districts.

3. The available levels of soil nutrients are the ones that are present in readily available form in the soil and hence are directly used and absorbed by the crop roots for their growth (Hodges, 1995).

4. It is to be noted that the problem of autocorrelation is associated with time series data and since the present study deals in cross sectional data that is why, the diagnostic test for autocorrelation was not performed for the regression models.

5. The proportional odds indicate the presence of separate intercept terms but a single odds ratio for the effect of each independent variable, which implies that the effects of independent variables are consistent (having same effect) across the different thresholds of the logistic model (Katz, 2011; Liu, 2009).

6. The conventional $\mathrm{R}^{2}$ (as used in least squares regression model) is not meaningful in logistic regression, hence measures similar to $\mathrm{R}^{2}$ called Pseudo $\mathrm{R}^{2}$ are used for logistic models. Cox and Snell is one such measure used in the present study, which explains the amount of variations in the logistic regression model as explained by the set of explanatory variables.

\section{Acknowledgment}

The author is grateful to University Grants Commission (UGC), New Delhi, India for providing research fellowship to support the doctoral research work pertaining to the present theme of the study.

\section{Funding Information}

No external funding was provided to prepare the present research article, however the author expresses the gratitude towards University Grants Commission (UGC), New Delhi, India for providing financial assistance in the form of research fellowship (UGC-Ref. No. 82/ NETJune 2009) to pursue doctoral research pertaining to the present theme of the study. 


\section{Ethics}

The author assures and confirms that the present study is a piece of original research work and has not been published elsewhere or is not being published or being considered for publication elsewhere.

\section{References}

Abrol, I.P., R.K. Gupta and R.K. Malik, 2005. Conservation agriculture-status and prospects. Centre for Advancement of Sustainable Agriculture, New Delhi.

Agresti, A., 2003. Categorical Data Analysis. 2nd Edn., John Wiley and Sons, New Jersey, ISBN-10: 0471458767, pp: 734.

Dhaliwal, S.S., S.S. Walia, M.K. Walia and J.S. Manchanda, 2013. Build up of macro, micro and secondary plant nutrients in site specific nutrient management experiment under ricewheat system. Int. J. Sci. Environ. Technol., 2: 236-244.

FAO and IFA, 2000. Fertilizers and their use. Food and Agriculture Organization and International Fertilizer Industry Association, Rome.

Field, A., 2005. Discovering Statistics Using SPSS. 2nd Edn., Sage Publications Ltd., London, ISBN-10: 0761944524.

Government of India, 2008. Guidelines for use of micronutrients, soil ameliorants and integrated nutrient management practices in NFSM States. Department of Agriculture and Cooperation, Ministry of Agriculture, New Delhi.

Government of India, 2011. Methods manual soil testing in India. Department of Agriculture and Cooperation, Ministry of Agriculture, New Delhi.

Government of India, 2012. Compendium on soil health. Department of Agriculture and Cooperation (INM Division), Ministry of Agriculture, Government of India, New Delhi.

Government of Punjab, 2011. Statistical abstract of Punjab. Economic Advisor to Government of Punjab, Economic and Statistical Organization, Chandigarh.

Greene, W.H., 2012. Econometric Analysis. 7th Edn., Pearson Education, Limited, Harlow, ISBN-10: 0273753568, pp: 1228.

Grover, D.K. and R. Singh, 2010. The Impact of macro management of agriculture scheme in Punjab. Agro Economic Research Centre, Punjab Agricultural University, Ludhiana.
Hodges, S.C., 1995. Soil fertility basics. North Carolina State University, North Carolina.

Katz, M.H., 2011. Multivariable Analysis: A Practical Guide for Clinicians and Public Health Researchers. 3rd Edn., Cambridge University Press, Cambridge, ISBN-10: 1139500317, pp: 164.

Kumar, S. and P. Singh, 2012. Determinants of total factor productivity growth for major agricultural crops in Punjab. Ind. J. Econ. Dev., 8: 49-62.

Liu, X., 2009. Ordinal regression analysis: Fitting the proportional odds model using Stata, SAS and SPSS. J. Modn. Applied Stats. Methods, 8: 632-645.

Malik, R.K., A. Yadav and S. Singh, 2005. Resource Conservation Technologies in Rice-Wheat Cropping System of Indo-Gangetic Plains, In: Conservation Agriculture-Status and Prospects, Abrol, I.P., R.K. Gupta and R.K. Malik (Eds.), Centre for Advancement of Sustainable Agriculture, New Delhi, pp: 13-22.

Patra, A.K., N.K. Lenka and A.K. Biswas, 2015. Soil health assessment and management: Issues and strategies. Ind. J. Fertilisers, 11: 16-25.

Sadana, U.S., 2011. Scenario of zinc deficiency in Punjab and its efficient management for increasing food grain production. Proceedings of the 3rd International Zinc Symposium (IZS' 11), Hyderabad.

Sadana, U.S., J.S. Manchanda, M.P.S. Khurana, S.S. Dhaliwal and H. Singh, 2010. The current scenario and efficient management of zinc, iron and manganese deficiencies. Better Crops South Asia, 4: 24-26.

Silvertooth, J.C., 2001. Soil Fertility and soil testing guidelines for Arizona cotton. The University of Arizona, Arizona.

Singh, M.V., R.P. Narwal, G. Bhupal Raj, K. Patel and U.S. Sadana, 2009. Changing scenario of micronutrient deficiencies in India during four decades and its impact on crop responses and nutritional health of humans and animals. Proceedings of the International Plant Nutrition Colloquium XVI, Department of Plant Sciences, UC Davis, California.

Tiwana, N.S., N. Jerath, S.S. Ladhar, G. Singh and R. Paul et al., 2007. State of environment punjab2007. Punjab State Council for Science and Technology, Chandigarh.

Verbree, C.L., J.A. Aitkenhead-Peterson, R.H. Loeppert, J.M. Awika and W.A. Payne, 2015. Shea (Vitellaria paradoxa) tree and soil parent material effects on soil properties and intercropped sorghum grain- $\mathrm{Zn}$ in southern Mali, West Africa. Plant Soil, 386: 21-33. 